\title{
Seven alternatives to evidence based medicine
}

David Isaacs, Dominic Fitzgerald

Departments of Education and Medicine, New Children's Hospital, Westmead, NSW 2145,

Australia

David Isaacs clinical professor

Dominic Fitzgerald staff physician

Correspondence to: D Isaacs davidi@nch.edu.au

BMJ 1999;319:1618
Clinical decisions should, as far as possible, be evidence based. So runs the current clinical dogma. ${ }^{12}$ We are urged to lump all the relevant randomised controlled trials into one giant meta-analysis and come out with a combined odds ratio for all decisions. Physicians, surgeons, nurses are doing $\mathrm{it}^{3-5}$; soon even the lawyers will be using evidence based practice. ${ }^{6}$ But what if there is no evidence on which to base a clinical decision?

\section{Participants, methods, and results}

We, two humble clinicians ever ready for advice and guidance, asked our colleagues what they would do if faced with a clinical problem for which there are no randomised controlled trials and no good evidence. We found ourselves faced with several personality based opinions, as would be expected in a teaching hospital. The personalities transcend the disciplines, with the exception of surgery, in which discipline transcends personality. We categorised their replies, on the basis of no evidence whatsoever, as follows.

Eminence based medicine-The more senior the colleague, the less importance he or she placed on the need for anything as mundane as evidence. Experience, it seems, is worth any amount of evidence. These colleagues have a touching faith in clinical experience, which has been defined as "making the same mistakes with increasing confidence over an impressive number of years." "The eminent physician's white hair and balding pate are called the "halo" effect.

Vehemence based medicine-The substitution of volume for evidence is an effective technique for brow beating your more timorous colleagues and for convincing relatives of your ability.

Eloquence based medicine-The year round suntan, carnation in the button hole, silk tie, Armani suit, and tongue should all be equally smooth. Sartorial elegance and verbal eloquence are powerful substitutes for evidence.

Providence based medicine-If the caring practitioner has no idea of what to do next, the decision may be best left in the hands of the Almighty. Too many clinicians, unfortunately, are unable to resist giving God a hand with the decision making.

Diffidence based medicine-Some doctors see a problem and look for an answer. Others merely see a problem. The diffident doctor may do nothing from a sense of despair. This, of course, may be better than doing

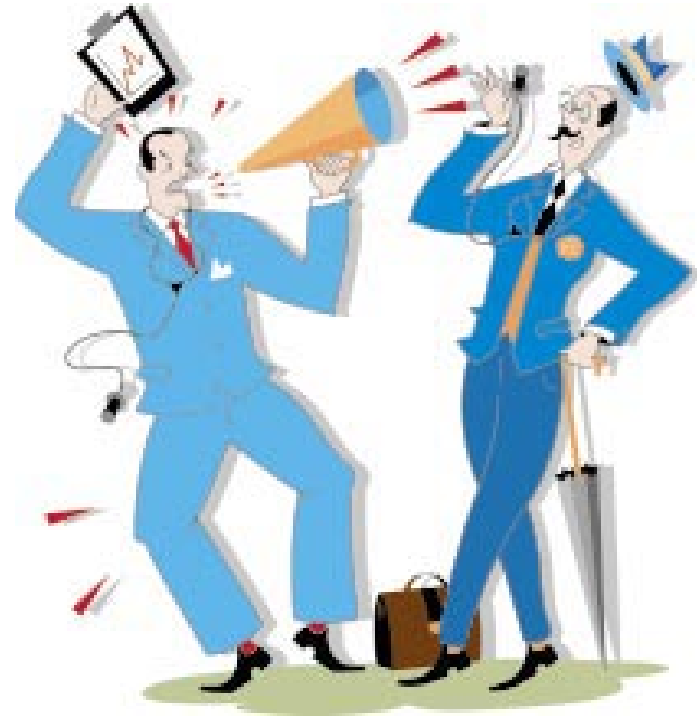

something merely because it hurts the doctor's pride to do nothing.

Nervousness based medicine-Fear of litigation is a powerful stimulus to overinvestigation and overtreatment. In an atmosphere of litigation phobia, the only bad test is the test you didn't think of ordering.

Confidence based medicine-This is restricted to surgeons (table).

\section{Comment}

There are plenty of alternatives for the practising physician in the absence of evidence. This is what makes medicine an art as well as a science.

Contributors: DI and DF each contributed half the jokes and will both act as guarantors.

Funding: None

Competing interests: None declared.

1 Evidence Based Medicine Working Group. Evidence-based medicine: a new approach to teaching the practice of medicine. JAMA 1992;268: 2420-5.

2 Rosenberg W, Donald A. Evidence based medicine: an approach to clinical problem solving. BMJ 1995;310:1122-6.

3 Sackett DL, Rosenberg WM, Gray JAM, Haynes RB, Richardson WS. Evidence based medicine: what it is and what it isn't. BMJ 1996;312:71-2.

4 Solomon MJ, McLeod RS. Surgery and the randomised controlled trial: past, present and future. Med J Aust 1998;169:380-3.

5 McClarey M. Implementing clinical effectiveness. Nursing Management 1998;5:16-9

6 EBM and the IMF.J Exponential Salaries 1999;99:1-9.

7 O'Donnell M. A sceptic's medical dictionary. London: BMJ Books, 1997.

Basis of clinical practice

\begin{tabular}{llll} 
Basis for clinical decisions & Marker & Measuring device & Unit of measurement \\
\hline Evidence & Randomised controlled trial & Meta-analysis & Odds ratio \\
\hline Eminence & Radiance of white hair & Luminometer & Optical density \\
\hline Vehemence & Level of stridency & Audiometer & Decibels \\
\hline Eloquence (or elegance) & Smoothness of tongue or nap of suit & Teflometer & Adhesin score \\
\hline Providence & Level of religious fervour & Sextant to measure angle of genuflection & International units of piety \\
\hline Diffidence & Level of gloom & Nihilometer & Sighs \\
\hline Nervousness & Litigation phobia level & Every conceivable test & Bank balance \\
\hline Confidence & Bravado & Sweat test & No sweat \\
\hline
\end{tabular}

${ }^{*}$ Applies only to surgeons. 